\section{Dental caries in Uruguayan adults and elders: findings from the first Uruguayan National Oral Health Survey}

\author{
Caries dental en adultos y adultos mayores \\ uruguayos: resultados del primer Estudio \\ Uruguayo de Salud Oral
}

\author{
Cárie dentária em adultos e idosos uruguaios: \\ resultados do primeiro Levantamento \\ Uruguaio de Saúde Bucal
}

\begin{abstract}
This study aimed to assess dental caries status and associated factors in Uruguayan adults and elders using data from the first Uruguayan National Oral Health Survey. Data were representative of the country as a whole. Sociodemographic information was collected with a closed questionnaire. Dental caries was assessed by clinical examination using the DMFT index. The final sample consisted of 769 participants. Mean DMFT was 15.20 and 24.12 for the 35-44 and 65-74-year age groups, respectively. Mean number of decayed teeth was 1.70 in adults and 0.66 in elders. Multivariate analyses showed higher prevalence of dental caries associated with age 65-74 years, low socioeconomic status, use of public dental services, presence of gingivitis; for decayed teeth, age 35-44 years, low socioeconomic status, use of public dental services, infrequent tooth brushing, need for oral health care, and presence of root caries showed higher severity. Uruguayan adults and elders from disadvantaged backgrounds concentrated a heavier burden of dental caries.
\end{abstract}

Dental Caries; Oral Health; Adult; Aged
Licet Álvarez 1 Judith Liberman 1 Soledad Abreu 1 Carolina Mangarelli 1 Marcos B. Correa 2

Flávio Fernando Demarco 2,3 Susana Lorenzo 1 Gustavo G. Nascimento ${ }^{2}$

\section{Resumen}

Este estudio tuvo como objetivo investigar las condiciones de caries y factores asociados en población adulta y adulta mayor uruguaya, a partir de datos del primer Estudio Uruguayo de Salud Oral. Los datos fueron representativos del país. Las condiciones socioeconómicas fueron evaluadas por cuestionarios. La caries dental fue evaluada por examen clínico, mediante el índice CPO-D. La muestra final evaluada fue de 769 personas. El CPO-D medio fue de 15,20 y 24,12 para los tramos de 35-44 años y de 65-74 años, respectivamente. La media de dientes cariados fue 1,70 entre los adultos y 0,66 entre los adultos mayores. Análisis multivariables mostraron una mayor severidad de caries: el tramo de 65-74 años, el bajo nivel socioeconómico, usuarios del servicio público de salud oral, y la presencia de sangrado gingival; mientras para caries sin tratar: el tramo de 35-44 años, el bajo nivel socioeconómico, el uso del servicio público de salud oral, el cepillado menor a dos veces al día, la necesidad auto-reportada para tratamiento dental y la presencia de caries radicular estuvieron asociadas. Adultos y adultos mayores uruguayos de bajo nivel socioeconómico concentran mayor carga de caries dental.

Caries Dental; Salud Bucal; Adulto; Anciano 


\section{Introduction}

Dental caries is defined as a chronic and cumulative disease with high prevalence worldwide, ranked among the ten most prevalent chronic conditions 1. Dental caries can be used as an important indicator of past disease experience, since it presents clear and objective clinical signs. The etiology comprises of a complex mix of biological, environmental, social, and behavioral factors 2 .

Some studies in recent decades have reported a decline in the prevalence of dental caries in high, medium, and low-income countries ${ }^{3}$. Most of these studies targeted the young population, focusing on school-age and preschool children, with little information on adults 4 . The World Health Organization (WHO) recommends epidemiological studies on the 35-44 and 65-74-year age groups due to their importance for describing and analyzing the cumulative damage of caries on oral health over the years and the effects of oral health care services in light of increasing life expectancy 5 .

Dental caries has been identified as the main cause of dental pain ${ }^{6}$ and can lead to tooth loss in advanced stages 7,8 . Damage caused by caries decreases individual quality of life and takes a high economic toll on both individuals and society, thus making the disease an important public health problem 9. Previous studies have shown wide disparities in oral health, since poor populations and medically compromised patients frequently present the worst oral health conditions 5. Important risk factors for dental caries in population groups include poverty, poor education, low socioeconomic status (SES), and lifestyle 10,11,12.

In South America, national surveys with samples of adults and elders have shown a high prevalence of dental caries. However only a few countries have presented representative population data, including Brazil, Colombia, and Chile, with values varying from $15 \%$ to $16.3 \%$ in the $35-44$-year age group and $19.6 \%$ to $27 \%$ in older adults $13,14,15$. These countries display similar social inequalities, with social and economic risk factors playing an important role in the occurrence of caries.

Uruguay is a country of three million inhabitants located in the southern region of South America. The country enjoys some of the best social indicators of Latin America, with a high Human Development Index (HDI = 0.792), low social disparity, and high life expectancy ${ }^{16}$. Data on dental caries status in Uruguay are scarce, with only one previous study presenting data on the rural population 17 and no information about the entire population. Considering Uruguay's high life expectancy, the lack of data about oral health conditions in Uruguayan adults and elders, and the country's social differences from other Latin American countries, the current study aimed to determine dental caries status and associated factors in the Uruguayan adult population aged 35-44 and 65-74 years, using data from the first Uruguayan National Oral Health Survey (2010-2011).

\section{Materials and methods \\ Study design and sample selection}

The study used a population-based cross-sectional design and was conducted in Uruguay from August 2010 to December 2011. The target population was Uruguayan adults aged 35-44 and 65-74 years living in cities with $\geq$ 20,000 inhabitants.

The samples were considered representative of the country's regions (capital area and countryside) and its 35-44 and 65-74-year age groups. The reference population was 851,926 individuals. Sample selection followed a multistage probabilistic cluster strategy. The primary sampling units were census tracts and the secondary units were households. The final sample comprised individuals from 15 cities, including Montevideo. The following parameters were also considered: $85 \%$ prevalence of dental caries, identified in the Brazilian Oral Health Survey (2003), 95\% confidence interval (95\%CI), and design effect of 1.5, plus a $20 \%$ non-response rate. Detailed information on the methodology was provided and discussed in depth by Lorenzo et al. 18 .

\section{Data collection}

Socioeconomic and demographic data, type of health service, and oral health conditions were assessed with a structured questionnaire, followed by a clinical oral examination. Socioeconomic status was assessed with the simplified version of the Index of Socioeconomic Status, validated for the Uruguayan population by the University of the Republic, School of Social Sciences 18,19 . The index uses the following information to define socioeconomic status: (a) head-of-household's occupation; (b) number of income-earning individuals in the household; (c) at least one family member with a university degree; (d) home appliances; (e) home furnishings; (f) at least one family member with an international credit card; and (g) car ownership. The resulting scores could range from 0 to 100 
allowing classification as low (0-29) versus medium/high SES (30-100) 18,19. The variable "type of dental health service" was recorded as public or private and referred to the most common type of health service used by the individual. The variable "tooth brushing frequency" was based on the question "How often do you usually brush your teeth?" and dichotomized as < twice a day versus $\geq$ twice a day. "Self-perceived need of dental care" (Do you think you need to visit a dentist currently?) was recorded, dichotomized as yes or no. Dental pain in the previous six months (yes/no) was assessed by the following question: "Have you experienced dental pain in the last 6 months?" The latter questions were based on the WHO stepwise approach to chronic disease risk factor surveillance.

Six previously trained and calibrated examiners performed the clinical examination. Calibration included theoretical activities, diagnosis of caries recorded in photographs, and clinical diagnosis conducted by a benchmark dental examiner 18. Before beginning the survey, the lowest intra-examiner unweighted Cohen's kappa was 0.67 for the CPO index, with 0.78 for interexaminer reproducibility. During the survey, data collection was repeated in 40 individuals from the sample. Intra-examiner unweighted Cohen's kappa was 0.67 to 118 . Clinical examination was conducted at the subject's home using artificial light, clinical mirror, and CPI periodontal probe (WHO). Dental caries was the dependent variable and was recorded according to the DMF-T index, of all erupted permanent teeth, excluding the third molars, according to 1997 WHO criteria. Root surfaces were also examined according to the DMF-T index, and root caries severity (DMF-T $\geq 1)$ and presence of decayed root (D component) were analyzed. Gingival bleeding was assessed with the CPI index at six sites of ten specific teeth and was categorized as absent or present ( $\geq 1$ site) 20 .

\section{Statistical analysis}

The data were analyzed with Stata 12.0 (Stata Corp., College Station, USA). Two different criteria were applied to define the outcome, as follows: (1) dental caries severity, considering total DMF-T; (2) decayed teeth (D component of DMF-T). Both outcomes were treated as count variables.

Descriptive and bivariate analyses were conducted for a preliminary assessment of the association between independent and outcome variables. Mean values and 95\%CI were obtained by simple linear regression. Multivariate Poisson regression models were used, considering the two different outcomes and the association with the independent variables. A conceptual model was used to order the inclusion of variables in the model: (1) distal variables (socio-demographic); and (2) proximal variables related to oral health status, following the model proposed by Victora et al. 21. Variables were adjusted for covariates at the same level of the model and higher. Rate ratios and their $95 \% \mathrm{CI}$ were estimated. The rate ratio corresponds to the ratio of mean DMF-T between the exposed and unexposed groups.

For independent variables, statistically significance was set at $\mathrm{p}<0.05$ after adjustment. All analyses were weighted to allow for design effect and the sample procedure used multivariate regression and "svy" command in Stata for data from complex samples.

\section{Ethical aspects}

The study protocol was approved by Ethics Research Committee of the University of the Republic School of Dentistry. All participants provided written informed consent.

\section{Results}

In the descriptive analysis, a total of 769 subjects were interviewed and clinically evaluated. The response rate was $74 \%$ in the national capital Montevideo and $61 \%$ in the countryside. The sample included 300 males (39\%) and 358 individuals 35-44-years of age (46.5\%). Considering the socioeconomic status, 283 (36.8\%) subjects were classified as low-income and $486(63.2 \%)$ as medium/high-income. Mean DMF-T was 15.20 (95\%CI: 14.24-16.16) in the 35-44-year group and 24.12 (95\%CI: 23.16-25.08) in the elders. As for the composition of DMF-T, the mean number of decayed teeth was 1.70 (95\%CI: 1.39-2.00) in the $35-44$-year group and 0.66 (95\%IC $0.48-0.84$ ) in elders. The mean number of restored teeth was 4.11 (95\%CI: 3.61-4.60) and 2.59 (95\%CI: 20.73.10 ), and mean number of missing teeth was 9.36 (95\%CI: 8.34-10.37) and 20.87 (95\%CI: 19.622.1 ) in adults and elders, respectively.

Caries prevalence (DMF-T $\geq 1$ ) was $99.5 \%$ in the 35-44-year group (95\%CI: 97.8-99.9), and $99.6 \%$ (95\%CI: 98.2-99.9) in the 65-74-year group. Prevalence rates for decayed teeth (D component $\geq 1$ ) were $55.9 \%$ and $28.9 \%$ in adults and elders, respectively. Table 1 shows the distribution of DMF-T in the sample. Greater severity of dental caries was associated with older age, low socioeconomic status, use of public dental services, less frequent brushing, gingival bleeding, and self-perceived need for dental care. 
Table 1

Mean DMF-T according to exposure variables in a sample of Uruguayan adults and elders, 2010-2011 $(n=769)$.

\begin{tabular}{|c|c|c|}
\hline Variables & Mean values $(95 \% \mathrm{Cl})$ & $p$-value * \\
\hline \multicolumn{3}{|l|}{ Socio-demographic variables - block 1} \\
\hline Sex & & 0.078 \\
\hline Female & $19.76(18.76-20.76)$ & \\
\hline Male & $17.46(16.23-18.69)$ & \\
\hline Age (years) & & $<0.001$ \\
\hline $35-44$ & $15.20(14.24-16.16)$ & \\
\hline $65-74$ & $24.12(23.16-25.08)$ & \\
\hline Region of the country & & 0.227 \\
\hline Countryside & $19.04(18.11-19.97)$ & \\
\hline National capital & $18.29(17.04-19.54)$ & \\
\hline Socioeconomic status & & $<0.001$ \\
\hline Low & $21.11(19.78-22.44)$ & \\
\hline Medium/High & $17.46(16.48-18.44)$ & \\
\hline Type of dental service & & $<0.001$ \\
\hline Public & $21.77(20.22-23.32)$ & \\
\hline Private & $17.55(16.54-18.57)$ & \\
\hline \multicolumn{3}{|l|}{ Oral health variables - block 2} \\
\hline Frequency of tooth brushing (times/day) & & 0.025 \\
\hline$\geq 2$ & $18.16(17.26-19.06)$ & \\
\hline$<2$ & $20.19(18.45-21.92)$ & \\
\hline Gingival bleeding ( $\geq 1$ site) & & $<0.001$ \\
\hline Yes & $20.48(19.25-21.71)$ & \\
\hline No & $16.83(15.82-17.83)$ & \\
\hline Self-perceived need of dental care & & $<0.001$ \\
\hline Yes & $17.80(16.87-18.74)$ & \\
\hline No & $20.67(19.16-22.18)$ & \\
\hline Dental pain in the previous six months & & 0.112 \\
\hline Yes & $18.15(16.57-19.73)$ & \\
\hline No & $18.78(17.85-19.71)$ & \\
\hline Root decay & & 0.330 \\
\hline Yes & $20.18(18.18-22.16)$ & \\
\hline No & $18.46(17.60-19.32)$ & \\
\hline
\end{tabular}

95\% $\mathrm{Cl}: 95 \%$ confidence interval.

* Linear regression.

Table 2 provides information on the distribution of decayed teeth according to the independent variables. Higher mean number of decayed teeth was associated with age 35-44 years, low socioeconomic status, use of public dental services, brushing teeth less than twice a day, selfperceived need of dental care, and presence of root caries.

Table 3 shows the crude and adjusted rate ratios for dental caries according to the independent variables. In the fitted model, the following variables remained associated with the outcome: older age $(\mathrm{RR}=1.56$; $95 \% \mathrm{CI}$ : $1.44-1.68)$, low so- cioeconomic status ( $\mathrm{RR}=1.11$; 95\%CI: 1.03-1.21), use of public dental services $(\mathrm{RR}=1.20$; $95 \% \mathrm{CI}$ : 1.11-1.31), and gingival bleeding $(\mathrm{RR}=1.10$; 95\%CI: 1.02-1.19).

Table 4 shows the crude and adjusted rate ratios for decayed teeth and exposure variables. After adjustment, age 35-44 years (RR = 2.69; 95\%CI: 1.92-3.77), low socioeconomic status (RR = 1.90; 95\%CI: 1.29-2.79), use of public dental services $(\mathrm{RR}=1.90 ; 95 \% \mathrm{CI}$ : 1.31-2.77), less frequent brushing $(\mathrm{RR}=1.67 ; 95 \% \mathrm{CI}$ : 1.19$2.35)$, self-perceived need of dental care $(R R=$ 3.83; 95\%CI: 2.52-5.83), and root caries ( $R R=$ 
Mean number of decayed teeth ( $\mathrm{D}$ component) according to exposure variables in a sample of Uruguayan adults and elders, 2010-2011 ( $n=769)$.

\begin{tabular}{|c|c|c|}
\hline Variables & Mean values $(95 \% \mathrm{Cl})$ & $p$-value * \\
\hline \multicolumn{3}{|l|}{ Socio-demographic variables - block 1} \\
\hline Sex & & 0.302 \\
\hline Female & $1.20(0.96-1.44)$ & \\
\hline Male & $1.40(1.07-1.73)$ & \\
\hline Age (years) & & $<0.001$ \\
\hline $35-44$ & $1.70(1.39-2.00)$ & \\
\hline $65-74$ & $0.66(0.48-0.84)$ & \\
\hline Region of the country & & 0.782 \\
\hline Countryside & $1.33(1.09-1.58)$ & \\
\hline Capital area & $1.28(0.97-1.59)$ & \\
\hline Socioeconomic position & & $<0.001$ \\
\hline Low & $2.02(1.59-2.45)$ & \\
\hline Medium/High & $0.96(0.76-1.16)$ & \\
\hline Type of dental service & & $<0.001$ \\
\hline Public & $2.16(1.64-2.69)$ & \\
\hline Private & $0.96(0.74-1.17)$ & \\
\hline \multicolumn{3}{|l|}{ Oral health variables - block 2} \\
\hline Frequency of tooth brushing (times/daily) & & $<0.001$ \\
\hline$\geq 2$ & $1.04(0.85-1.23)$ & \\
\hline$<2$ & $2.18(1.60-2.75)$ & \\
\hline Presence of gingival bleeding ( $\geq 1$ site) & & 0.070 \\
\hline Yes & $1.58(1.24-1.91)$ & \\
\hline No & $1.03(0.83-1.25)$ & \\
\hline Self-perceived need of dental care & & $<0.001$ \\
\hline Yes & $1.71(1.43-1.98)$ & \\
\hline No & $0.29(0.18-0.40)$ & \\
\hline Dental pain in the previous six months & & 0.017 \\
\hline Yes & $1.69(1.20-2.18)$ & \\
\hline No & $1.19(0.97-1.41)$ & \\
\hline Root decay & & $<0.001$ \\
\hline Yes & $3.57(2.57-4.58)$ & \\
\hline No & $1.13(0.94-1.33)$ & \\
\hline
\end{tabular}

95\% Cl: 95\% confidence interval.

* Linear regression.

2.06; 95\%CI: 1.49-2.91) were associated with the outcome.

\section{Discussion}

Our findings showed that even after adjustment, greater severity of dental caries and more decayed teeth were associated with lower socioeconomic status, use of public dental services, and poor oral hygiene and oral conditions, as observed in previous studies $22,23,24$. As far as we know, this was the first population-based study presenting data on dental caries status in Uruguayan adults and elders.

Although Uruguay boasts one of the highest human development indices in Latin America, it is not reflected in the adult population's oral health conditions. The high prevalence of caries $(99.5 \%$ and $99.6 \%$ in the 35-44 and 65-74-year groups, respectively) and experience of caries (DMF-T $=15.20$ and 24.12 in the two age groups, respectively) were similar to those found in Colombia ${ }^{15}$, Brazil ${ }^{14}$, and Chile ${ }^{13}$. DMF-T presents 
Crude and adjusted rate ratios (RR) for DMF-T according to explanatory variables in Uruguayan adults and elders $(\mathrm{n}=769)$,

2010-2011. Poisson regression analysis.

\begin{tabular}{|c|c|c|c|c|}
\hline \multirow[t]{2}{*}{ Variables } & \multicolumn{4}{|c|}{ DMF-T } \\
\hline & $\mathrm{RR} *(95 \% \mathrm{Cl})$ & p-value & $\mathrm{RR} * \star(95 \% \mathrm{Cl})$ & p-value \\
\hline \multicolumn{5}{|l|}{ Socio-demographic variables - block 1} \\
\hline Sex & & 0.043 & & 0.117 \\
\hline Male & $0.88(0.80-0.96)$ & & $0.92(0.86-1.04)$ & \\
\hline Female & 1.00 & & 1.00 & \\
\hline Age (years) & & $<0.001$ & & $<0.001$ \\
\hline $35-44$ & 1.00 & & 1.00 & \\
\hline $65-74$ & $1.58(1.47-1.71)$ & & $1.56(1.44-1.68)$ & \\
\hline Region of the country & & 0.035 & & 0.343 \\
\hline Countryside & 1.00 & & 1.00 & \\
\hline National capital & $0.96(0.88-1.04)$ & & $0.96(0.89-1.04)$ & \\
\hline Socioeconomic status & & $<0.001$ & & 0.007 \\
\hline Low & $1.20(1.11-1.31)$ & & $1.11(1.03-1.21)$ & \\
\hline Medium/High & 1.00 & & 1.00 & \\
\hline Type of dental service & & $<0.001$ & & $<0.001$ \\
\hline Public & $1.24(1.13-1.35)$ & & $1.20(1.11-1.31)$ & \\
\hline Private & 1.0 & & 1.00 & \\
\hline \multicolumn{5}{|l|}{ Oral health variables - block 2} \\
\hline Frequency of brushing (times/day) & & 0.037 & & 0.131 \\
\hline$\geq 2$ & 1.00 & & 1.00 & \\
\hline$<2$ & $1.11(1.00-1.22)$ & & $1.07(0.98-1.19)$ & \\
\hline Gingival bleeding ( $\geq 1$ site) & & $<0.001$ & & $<0.001$ \\
\hline Yes & $1.21(1.11-1.32)$ & & $1.10(1.02-1.19)$ & \\
\hline No & 1.00 & & 1.00 & \\
\hline Self-perceived need of dental care & & 0.008 & & 0.663 \\
\hline Yes & $1.16(1.06-1.27)$ & & $1.02(0.94-1.09)$ & \\
\hline No & 1.00 & & 1.00 & \\
\hline Dental pain in the previous six months & & 0.502 & & 0.863 \\
\hline Yes & $0.97(0.87-1.07)$ & & $1.01(0.91-1.11)$ & \\
\hline No & 1.00 & & 1.00 & \\
\hline Root caries experience & & 0.110 & & 0.239 \\
\hline Yes & $1.09(0.98-1.22)$ & & $1.02(0.98-1.06)$ & \\
\hline No & 1.00 & & 1.00 & \\
\hline
\end{tabular}

95\% $\mathrm{Cl}$ : 95\% confidence interval.

* RR crude;

** RR adjusted.

important limitations for evaluating real dental caries status, since the index reflects lifetime experience of dental caries, without specifying each current component 22. Exploring each component separately is important for identifying the population's real needs in terms of prevention, treatment, and rehabilitation.

Despite the decline in dental caries prevalence, social and economic inequalities have led to an increase in the most vulnerable groups
$2,22,23$. Our results showed a low number of decayed teeth in Uruguayan adults and elders, following the worldwide trend. Despite the low values, presence of decayed teeth remained associated with low socioeconomic status in the adjusted model. The results are corroborated by Narvai et al. ${ }^{24}$, who defined this event as "dental caries polarization", a common phenomenon in Latin America. According to the authors, this concept can be defined as the occurrence of a 
Crude and adjusted rate ratios (RR) for decayed teeth (D component) in a sample of Uruguayan adults and elders, 2010-2011.

Poisson regression analysis $(n=769)$.

\begin{tabular}{|c|c|c|c|c|}
\hline \multirow[t]{2}{*}{ Variables } & \multicolumn{4}{|c|}{ Decayed teeth } \\
\hline & $\mathrm{RR} *(95 \% \mathrm{Cl})$ & p-value & $\mathrm{RR} * \star(95 \% \mathrm{Cl})$ & $\mathrm{p}$-value \\
\hline \multicolumn{5}{|l|}{ Socio-demographic variables - block 1} \\
\hline Sex & & 0.335 & & 0.381 \\
\hline Male & $1.16(0.85-1.57)$ & & $1.15(0.83-1.57)$ & \\
\hline Female & 1.00 & & 1.00 & \\
\hline Age (years) & & $<0.001$ & & $<0.001$ \\
\hline $35-44$ & $2.55(1.85-3.52)$ & & $2.69(1.92-3.77)$ & \\
\hline $65-74$ & 1.00 & & 1.00 & \\
\hline Region of the country & & 0.782 & & 0.970 \\
\hline Countryside & 1.00 & & 1.00 & \\
\hline National capital & $0.95(0.70-1.29)$ & & $1.01(0.73-1.38)$ & \\
\hline Socioeconomic status & & $<0.001$ & & 0.001 \\
\hline Low & $2.10(1.56-2.84)$ & & $1.90(1.29-2.79)$ & \\
\hline Medium/high & 1.00 & & 1.00 & \\
\hline Type of dental service & & $<0.001$ & & 0.001 \\
\hline Public & $2.26(1.62-3.14)$ & & $1.90(1.31-2.77)$ & \\
\hline Private & 1.00 & & 1.00 & \\
\hline \multicolumn{5}{|l|}{ Oral health variables - block 2} \\
\hline Frequency of brushing (times/day) & & $<0.001$ & & 0.003 \\
\hline$\geq 2$ & 1.00 & & 1.00 & \\
\hline$<2$ & $2.09(1.51-2.88)$ & & $1.67(1.19-2.35)$ & \\
\hline Gingival bleeding ( $\geq 1$ site) & & $<0.001$ & & 0.136 \\
\hline Yes & $1.52(1.13-2.04)$ & & $1.27(0.92-1.74)$ & \\
\hline No & 1.00 & & 1.00 & \\
\hline Self-perceived need of dental care & & $<0.001$ & & $<0.001$ \\
\hline Yes & $5.85(3.92-8.73)$ & & $3.83(2.52-5.83)$ & \\
\hline No & 1.00 & & 1.00 & \\
\hline Dental pain in the previous six months & & 0.047 & & 0.313 \\
\hline Yes & $1.41(1.00-1.99)$ & & $1.17(0.86-1.61)$ & \\
\hline No & 1.00 & & 1.00 & \\
\hline Root decay & & $<0.001$ & & $<0.001$ \\
\hline Yes & $3.13(2.24-4.35)$ & & $2.06(1.49-2.91)$ & \\
\hline No & 1.00 & & 1.00 & \\
\hline
\end{tabular}

95\% Cl: $95 \%$ confidence interval.

* RR crude;

** RR adjusted.

large number of disease-free individuals, while a few individuals suffer the brunt of the caries burden, reflecting exposure to social inequalities, even in oral health 25,26 .

Low income has been closely associated with low schooling 27, where poor individuals display limited knowledge of caries prevention and thus show higher caries rates ${ }^{28}$. Individuals with lower socioeconomic status use health services less frequently, and mostly use public health services 29. Corroborating this assumption, our results showed that both outcomes, DMF-T and decayed teeth, were statistically associated with low income and use of public health services. In developing countries, the type of health care system reflects socioeconomic status, since disadvantaged individuals cannot afford health insurance or out-of-pocket healthcare. We thus presume that the type of treatment is applied across different socioeconomic classes accord- 
ing to the type of health services used. Subjects from the lowest socioeconomic status concentrate a higher burden of dental caries and consequently are more prone to tooth extraction, the most common treatment for dental caries offered in public healthcare services in developing countries 30 . Meanwhile, wealthier individuals tend to seek regular private preventive care, with periodic routine appointments, resulting in fewer decayed teeth and lower DMF-T 29. In Uruguay specifically, tooth extraction is the only treatment of caries for adults and elders provided by public healthcare services, since there are no preventive measures specifically targeting these population groups.

Self-perceived need of dental care and use of public healthcare services were also statistically associated with tooth decay. In our study, subjects with decayed teeth perceived their need for dental care, but failed to seek treatment. Since dental caries was also associated with use of public healthcare services and low socioeconomic status, the study indicates that the Uruguayan health care system is not prepared to treat oral health problems in disadvantaged people, even when this need is perceived. A study by Camargo et al. 29 found similar associations when evaluating the use of dental services in Brazil. According to the authors, individuals that reported the need for dental care were associated with use of public services, suggesting that inequality in oral health is common to Latin American countries 22.

In the adjusted model, DMF-T was associated with older age, while the number of decayed teeth was higher in middle-aged adults. According to previous findings, this could be explained by the cumulative nature of the DMF-T index. Older adults probably experienced more dental caries over the course of life and treated caries according to their past needs and conditions 30,31 . Additionally, in the early 1990s, Uruguay simultaneously adopted community water fluoridation and an important change in the dentistry school curriculum, focusing on a more preventive model with a humanistic and holistic approach, following the global trend. These new circumstances may have created differences in oral health within the adult and elderly population, as observed previously in Brazil and Bulgaria 14,32. We therefore assume that this explains the difference in DMF-T scores between the two age groups. In the D component, the presence of more decayed teeth in adults could be explained simply by the presence of more remaining teeth, since the elders did not experience the paradigm shift in oral health care or the effects of fluoridation, thus being more susceptible to tooth extraction in the past 30 , which may appear as higher DMF-T.
Infrequent tooth brushing, gingival bleeding, and decayed roots were also associated with tooth crown decay. The relationship between oral hygiene and dental caries is well described in the literature 4,33 , as is gingival bleeding 34 , since it is linked to frequency of dental biofilm removal and contact with fluoride. A positive association between root and coronal caries has been reported. Investigating the root caries occurrence at age 38 years in a birth cohort, Thomson et al. 35 observed that lifetime coronal caries experience was a risk factor for root surface caries experience. Importantly, the study design (crosssectional) probably affected this association inversely, since previous studies demonstrated that coronal caries are considered risk factors for root caries, especially in older adults, when gingival recession is more frequent 36,37 .

Our study presents some important limitations that should be considered. First, the crosssectional design is not appropriate for establishing casual and temporal relations between the exposure and outcome variables. However, this design is useful for elucidating the population profile, indicating future directions for longitudinal studies and public policies. Second, the response rate was low when compared to similar studies ${ }^{14}$. As described by Lorenzo et al. ${ }^{18}$, statistical adjustment for sex and age was performed to balance the sample. This statistical approach guaranteed that the sample was representative of the entire country, but resulted in loss of precision, as expressed by wider confidence intervals. Finally, even after adjustment, we cannot assume that the sample is not biased, since the oral health conditions of non-responding individuals remain unknown.

These limitations notwithstanding, the study provides representative population information on dental caries in Uruguayan adults and elders. Our findings showed that even in a different social scenario from other Latin American countries, dental caries status behaves similarly, concentrated in individuals with low socioeconomic status. Our study was also the first to indicate that public dental services in Uruguay need to focus on vulnerable groups, with a preventive approach, since dental care reflects a practice based on surgical solutions to biological problems, especially in the poor. Public policies in Uruguay should thus focus on reducing inequalities in oral health. 


\section{Resumo}

Este estudo objetivou investigar as condições de cárie dentária e fatores associados na população adulta e idosa uruguaia com base nos dados oriundos do primeiro Levantamento Uruguaio de Saúde Bucal. Os dados foram representativos do país. Condições socioeconômicas foram coletadas por meio de questionários. Cárie dentária foi avaliada por meio de exame clínico com o uso do índice CPO-D. A amostra total examinada foi de 769 participantes. O CPO-D médio foi 15,20 e 24,12 para os grupos de 35-44 anos e de 65-74 anos, respectivamente. A média de dentes cariados foi 1,70 entre os adultos e 0,66 entre os idosos. Análises multivariadas demonstraram maior severidade de cárie dentária: grupo 65-74 anos, baixa posição socioeconômica, usuários do serviço público de saúde bucal, e presença de sangramento gengival; $e$, para dentes cariados: grupo de 35-44 anos, baixa posição socioeconômica, uso de serviço público para saúde bucal, escovação menor que duas vezes ao dia, necessidade de tratamento dentário autopercebido, e presença de cárie radicular se mostraram associados. Adultos e idosos em condições socioeconômicas mais baixas apresentam maior concentração de cárie dentária.

Cárie Dentária; Saúde Bucal; Adulto; Idoso

\section{Contributors}

L. Álvarez, J. Liberman, S. Abreu, and C. Mangarelli participated in the data analysis and interpretation, and in the drafting and revision of the final version for publication. M. B. Correa and F. F. Demarco participated in the drafting and revision of the final version. S. S. Lorenzo participated in the study's conception and design and in the critical revision of the final version. G. G. Nascimento participated in the article's conception, data analysis and interpretation, and drafting and revision of the final version.

\section{Acknowledgments}

The authors with to thank the Scientific Research Commission of the University of the Republic (UDELAR Uruguay) and the School of Dentistry, University of the Republic for supporting and sponsoring all stages of the study.

\section{Conflict of interest}

The authors declare no conflict of interest.

\section{References}

1. Marcenes W, Kassebaum NJ, Bernabe E, Flaxman A, Naghavi M, Lopez A, et al. Global burden of oral conditions in 1990-2010: a systematic analysis. J Dent Res 2013; 92:592-7.

2. Thomson WM. Social inequality in oral health. Community Dent Oral Epidemiol 2012; 40 Suppl 2:28-32.

3. Marthaler TM. Changes in dental caries 1953 2003. Caries Res 2004; 38:173-81.

4. Lu HX, Wong MC, Lo EC, McGrath C. Risk indicators of oral health status among young adults aged 18 years analyzed by negative binomial regression. BMC Oral Health 2013; 13:40.

5. Petersen PE, Bourgeois D, Bratthall D, Ogawa H. Oral health information systems - towards measuring progress in oral health promotion and disease prevention. Bull World Health Organ 2005; 83:686-93
6. Boeira GF, Correa MB, Peres KG, Peres MA, Santos IS, Matijasevich A, et al. Caries is the main cause for dental pain in childhood: findings from a birth cohort. Caries Res 2012; 46:488-95.

7. Selwitz RH, Ismail AI, Pitts NB. Dental caries. Lancet 2007; 369:51-9.

8. Susin C, Oppermann RV, Haugejorden O, Albandar JM. Tooth loss and associated risk indicators in an adult urban population from south Brazil. Acta Odontol Scand 2005; 63:85-93.

9. Fejerskov O, Kidd E. Dental caries: the disease and its clinical management. Oxford: Blackwell Munsksgaard; 2008.

10. Sheiham A, Alexander D, Cohen L, Marinho V, Moyses S, Petersen PE, et al. Global oral health inequalities: task group-implementation and delivery of oral health strategies. Adv Dent Res 2011; 23:259-67. 
11. Touger-Decker R, van Loveren C. Sugars and dental caries. Am J Clin Nutr 2003; 78:881S-92S.

12. Petersen PE, Yamamoto T. Improving the oral health of older people: the approach of the WHO Global Oral Health Programme. Community Dent Oral Epidemiol 2005; 33:81-92.

13. Urzua I, Mendoza C, Arteaga O, Rodriguez G, Cabello R, Faleiros S, et al. Dental caries prevalence and tooth loss in chilean adult population: first national dental examination survey. Int J Dent 2012; 2012:810170.

14. Departamento de Atenção Básica, Secretaria de Atenção à Saúde, Ministério da Saúde. Projeto SB Brasil 2010. Condições de saúde bucal da população brasileira 2010-2011: resultados principais. Brasília: Ministério da Saúde; 2011.

15. Ministerio de Salud. III Estudio Nacional de Salud Bucal - ENSAB III. II Estudio de Factores de Riesgo de las Enfermedades Crónicas - ENFREC II. Bogotá: Ministerio de Salud; 1999.

16. United Nations Development Programme. Human development report 2013. https://data.undp.org/ dataset/Table-1-Human-Development-Indexand-its-components/wxub-qc5k (accessed on 24/ Jan/2014).

17. Olmos P, Piovesan S, Lorenzo S, Mass F. Caries dental. La enfermedad oral más prevalente Primer Estudio poblacional en jóvenes y adultos uruguayos del interior del país. Odontoestomatología 2013; $15 \mathrm{~N}$ Esp:26-34.

18. Lorenzo S, Álvarez R, Blanco S, Peres M. Primer Relevamiento Nacional de Salud Bucal en población joven y adulta uruguaya. Aspectos metodológicos. Odontoestomatología 2013; 15 N Esp:8-25.

19. Facultad de Sociología, Universidad de la República. Validación del índice de nivel socio económico para estudios de mercado y opinión pública. http://www.audap.com.uy/documentos/ publicacion_inse_nacional.pdf (accessed on 30/ Apr/2012).

20. World Health Organization. Oral health surveys: basic methods. Geneva: World Health Organization; 1997.

21. Victora CG, Huttly SR, Fuchs SC, Olinto MTA. The role of conceptual frameworks in epidemiological analysis: a hierarchical approach. Int J Epidemiol 1997; 26:224-7.

22. Antunes JL, Narvai PC, Nugent ZJ. Measuring inequalities in the distribution of dental caries. Community Dent Oral Epidemiol 2004; 32:41-8.

23. Oliveira LJ, Correa MB, Nascimento GG, Goettems ML, Tarquinio SB, Torriani DD, et al. Iniquidades em saúde bucal: escolares beneficiários do Bolsa Família são mais vulneráveis? Rev Saúde Pública 2013; 47:1039-47.

24. Narvai PC, Frazão P, Roncalli AG, Antunes JLF. Cárie dentária no Brasil: declínio, polarização, iniquidade e exclusão social. Rev Panam Salud Pública 2006; 19:385-93.
25. Tickle M. The 80:20 phenomenon: help or hindrance to planning caries prevention programmes? Community Dent Health 2002; 19:39-42.

26. Macek MD, Heller KE, Selwitz RH, Manz MC. Is 75 percent of dental caries really found in 25 percent of the population? J Public Health Dent 2004; 64:20-5.

27. Piovesan C, Padua MC, Ardenghi TM, Mendes FM, Bonini GC. Can type of school be used as an alternative indicator of socioeconomic status in dental caries studies? A cross-sectional study. BMC Med Res Methodol 2011; 11:37.

28. Kamppi A, Tanner T, Pakkila J, Patinen P, Jarvelin MR, Tjaderhane L, et al. Geographical distribution of dental caries prevalence and associated factors in young adults in Finland. Caries Res 2013; 47:346-54.

29. Camargo MB, Dumith SC, Barros AJ. Uso regular de serviços odontológicos entre adultos: padrões de utilização e tipos de serviços. Cad Saúde Pública 2009 ; 25:1894-906.

30. Nguyen TC, Witter DJ, Bronkhorst EM, Truong NB, Creugers NH. Oral health status of adults in Southern Vietnam: a cross-sectional epidemiological study. BMC Oral Health 2010; 10:2.

31. Mamai-Homata E, Margaritis V, Koletsi-Kounari H, Oulis C, Polychronopoulou A, Topitsoglou V. Tooth loss and oral rehabilitation in Greek middle-aged adults and senior citizens. Int J Prosthodont 2012; 25:173-9.

32. Damyanov ND, Witter DJ, Bronkhorst EM, Creugers NH. Dental status and associated factors in a dentate adult population in Bulgaria: a crosssectional survey. Int J Dent 2012; 2012:578401.

33. Gilbert GH, Duncan RP, Shelton BJ. Social determinants of tooth loss. Health Serv Res 2003; 38:1843-62.

34. Nascimento GG, Seerig LM, Vargas-Ferreira F, Correa FO, Leite FR, Demarco FF. Are obesity and overweight associated with gingivitis occurrence in Brazilian schoolchildren? J Clin Periodontol 2013; 40:1072-8.

35. Thomson WM, Broadbent JM, Foster Page LA, Poulton R. Antecedents and associations of root surface caries experience among 38-year-olds. Caries Res 2013; 47:128-34.

36. Mamai-Homata E, Topitsoglou V, Oulis C, Margaritis V, Polychronopoulou A. Risk indicators of coronal and root caries in Greek middle-aged adults and senior citizens. BMC Public Health 2012; 12:484.

37. Gokalp S, Dogan BG. Root caries in 35-44 and 6574 year-olds in Turkey. Community Dent Health 2012; 29:233-8.

Submitted on $01 /$ Sep/2014

Final version resubmitted on 17/Dec/2014

Approved on 02/Mar/2015 